\title{
Impact of environmental endocrine disrupting chemicals on the development of obesity
}

\author{
Retha R. Newbold ${ }^{1}$ \\ Developmental Endocrinology and Endocrine Disruptor Section, Laboratory of Molecular Toxicology, and National \\ Toxicology Program, National Institute of Environmental Health Sciences, NIH, DHHS, Research Triangle Park, \\ North Carolina, USA
}

\begin{abstract}
Environmental chemicals with hormone-like activity can disrupt programming of endocrine signaling pathways during development and result in adverse effects, some of which may not be apparent until much later in life. Recent reports link exposure to environmental endocrine disrupting chemicals during development with adverse health consequences, including obesity and diabetes. These particular diseases are quickly becoming significant public health problems and are fast reaching epidemic proportions worldwide. This review summarizes data from experimental animals and humans which support an association of endocrine disrupting chemicals, such as diethylstilbestrol, bisphenol A, phytoestrogens, phthalates, and organotins, with the development of obesity. Potential mechanisms are summarized and future research needs are discussed.
\end{abstract}

Key words: Bisphenol A, Diabetes, Endocrine disruptors, Metabolic disease, Obesogens, Phthalates, Tributytin, Xenoestrogens

\section{INTRODUCTION}

Obesity, defined as a body mass index (BMI) greater than $30 \%$ in adults, has been identified as a significant public health problem..$^{1-3}$ Over the last 2 to 3 decades, the prevalence of obesity has risen dramatically in wealthy industrialized countries, and also in poorer underdeveloped nations where it often coexists with under-nutrition. ${ }^{4}$ In the United States,

Address for correspondence:

Retha R. Newbold, 127 Radcliff Circle, Durham,

NC 27713, Tel.: +919-541-0738; +919-544-1268,

E-mail: newbold1@niehs.nih.gov; newboldretha.hotmail.com

Received 11-02-10, Revised 29-04-10, Accepted 20-05-10 the Center for Disease Control (CDC) reported in 2008 that obesity has reached epidemic proportions with more than $60 \%$ of U.S. adults being either obese or overweight. ${ }^{5}$ Similar statistics have been reported for many European countries, the Middle East, Australia, and China. The reasons for this sharp increase in overweight/obesity are not well understood but factors such as high fructose diets, genetics/epigenetics, increased maternal age, sleep debt, use of certain pharmaceuticals, and the built environment have all been proposed as playing a role. ${ }^{6}$

${ }^{1}$ Research was conducted while the author was employed by NIEHS; the author is currently a visiting scientist at NIEHS 
Obesity is a problem for all ages, but it is of particular concern for children since most obese and overweight children grow up to be obese adults. The number of children and adolescents who are overweight, or at risk for being overweight, has risen in parallel with that reported in adults. ${ }^{7}$ Although a recent study found that the increase in obesity has stopped its upward trend in the last few years, there is no indication of any decrease in prevalence. ${ }^{8}$ Prevention of obesity is a very important area of research since it is such a challenge to treat obesity effectively once established.

Obesity is a complex disease, affecting virtually all ages, races, sexes, and socioeconomic groups, with serious social and psychological repercussions. Further, obesity and overweight are major contributors to the global burden of chronic diseases and are associated with Type 2 diabetes, hyper-insulinemia, insulin resistance, coronary heart disease, high blood pressure, stroke, gout, liver disease, asthma and pulmonary problems, gall bladder disease, kidney disease, reproductive problems, osteoarthritis, and some forms of cancer. ${ }^{9-11}$ Frequently, many of these illnesses are being reported in children who are overweight or obese, whereas in the past these diseases were only seen in older individuals. Health professionals predict that our current generation of children may be the first in history to experience a shorter life expectancy than their parents due to the impact of obesity-related diseases.

Obesity is most likely caused by a complicated interaction between genetic, behavioral, and environmental factors. However, the most common causes are thought to be overeating high calorie fatty diets combined with a sedentary lifestyle which is imposed on a background of genetic predisposition for the disease. Although much interest has centered on these factors, with a specific focus on incorporating healthy foods in our diets and more exercise in our lifestyle, the exact etiology of obesity is unknown. It is still puzzling why some people find it so difficult to lose weight, and keep it off, regardless of diet and/or exercise. Interestingly, one environmental factor that is recently receiving attention is the contribution of endocrine disrupting chemicals (EDCs) to the high prevalence of obesity.
EDCs can interfere with normal function of the endocrine system by affecting the balanced system of glands and hormones that regulate vital body functions including growth, stress response, sex development, gender behavior, ability to reproduce, production and utilization of insulin, and metabolic rate. Research advances, based on experiments in animals, confirm that EDCs can disrupt the gene-controlled, normal signaling systems that determine every aspect of fetal development.

Recent epidemiology studies also indicate that exposure to EDCs during development is associated with overweight and obesity later in life. For example, high serum Polychlorinated Bisphenyls (PCBs) levels have been associated with high levels of total serum lipids and BMI in a Native American cohort, ${ }^{12}$ and prenatal and early life PCB exposures were associated with increased weight in boys and girls at puberty. ${ }^{13}$ Other studies report a link between some persistent organic pollutants and increased body weight and diabetes $;{ }^{14}$ furthermore, non-dioxin PCBs were shown to be inversely associated with BMI but organochlorine pesticides to be positively associated with BMI. ${ }^{15,16}$ These data support earlier findings which also reported a positive correlation between plasma organochlorine concentrations and BMI and fat mass. ${ }^{17}$ Also, studies focusing on in utero exposure linked hexachlorobenzene exposure during pregnancy to a higher risk of overweight in children at 6 years of age. ${ }^{18}$

In a cross-sectional study, concentrations of urinary phthalates metabolites were associated with increased waist circumference and insulin resistance in adult males in the United States $;{ }^{19}$ another study reported similar findings in the U.S. National Health and Nutrition Examination Survey (NHANES ) participants, although different effects were seen with the various metabolites. ${ }^{20}$

Other studies support an association of BPA with disease such as obesity; high BPA levels were detected in both non-obese and obese women with polycystic ovarian syndrome (PCOS) compared with BPA levels in non-obese normal women, suggesting possible involvement of BPA in PCOS and/or obesity development. ${ }^{21}$ With regard to heavy metals, arsenic exposure has been associated with Type 2 diabetes 
in a Mexican cohort ${ }^{22}$ and in US adults. ${ }^{23}$

Taken together, these epidemiological reports suggest that environmental exposures to various endocrine disrupting chemicals play a role in overweight /obesity and the various complications such as diabetes that are associated with these diseases. Since there are so many diverse chemicals involved, they are most likely exerting their effects through multiple pathways.

\section{THE DEVELOPMENTAL ORIGINS OF ADULT DISEASE}

Although adult exposure to endocrine-disrupting substances is important, exposure of the developing fetus or infant is of particular concern..$^{24-27}$ The developing fetus and neonate are particularly sensitive to perturbation by endocrine disrupting chemicals because the placenta does not completely protect the unborn fetus from its external environment and the organism undergoes periods of extremely rapid cell division and differentiation thus resulting in cells that can differentiate abnormally and pass altered programming to subsequent generations. In many cases, the damage that occurs prenatally is irreversible, while adult exposure is usually reversible. Moreover, the developing organism lacks the protective mechanisms that are available to the adult such as DNA repair mechanisms, a fully competent immune system, detoxifying enzymes, liver metabolism, and has an immature blood/ brain barrier. ${ }^{24}$ Also, the developing fetus and neonate have increased metabolic rates as compared to adults which in some cases may make them more vulnerable to chemical toxicity. It is now well established in the fields of nutrition and endocrine disruption that exposure to environmental chemicals during development can interfere with complex differentiating endocrine signaling pathways and cause adverse consequences later in life, ${ }^{28,29}$ the well known reproductive tract toxicity of diethylstilbestrol (DES) is one of the best examples of adverse consequences of endocrine disrupting chemicals [for review, see $(24,30)]$. The concept of the "developmental origins of adult disease", ${ }^{31}$ as the term implies, suggests that there is a time lag between exposure and manifestation of disease. In other words, the effects of exposure during development may not be readily apparent until much later in life.
Another key concept in the field of endocrine disruption is that there may be non-traditional dose response curves such as an inverted " $U$ " or even multiple "U" shaped curves ${ }^{32}$ making it impossible to predict responses in the low dose environmental exposure range based on exposures in the high dose range. Further, because of the increased sensitivity of differentiating tissues, chemicals can actually exert effects at very low levels of exposure. Although these concepts have been well accepted for hormones and neurotransmitters, they are just starting to be appreciated for endocrine disrupting substances.

Transgenerational effects may also be seen following exposure to endocrine disrupting chemicals during development, not only to the exposed individual but also to subsequent generations. This would imply that the mechanisms of transmission occur through the germ line and they may involve genetic and/or epigenetic events. In the case of epigenetic changes, effects are not due to a genetic impairment but to a modification of factors that regulate gene expression such as DNA methylation and histone acetylation. Thus far, endocrine disrupting studies have mainly focused on epigenetic changes in reproductive tract tissues. ${ }^{33-38}$ However, similar effects can conceivably occur in other differentiating endocrine responsive tissues.

Recently, a new target of endocrine disrupting chemicals has been proposed, the adipocyte. A newly emerging hypothesis is that exposure to environmental chemicals during development may play a role in the development of obesity later in life. ${ }^{27,39-44}$ These chemicals have been termed "obesogens" based on the idea that they inappropriately regulate lipid metabolism and adipogenesis promoting obesity. ${ }^{45}$ In vitro studies have described the disruptive effects of environmental chemicals on normal adipocyte development as well as on homeostatic control of adipogenesis and early energy balance. ${ }^{45,46}$ Further, numerous experimental animal studies also describe an association of obesity and exposure to various environmental chemicals during development. Although uncertainties remain about the full extent of health consequences that follow exposure to environmental chemicals, especially low dose exposures that are relevant to the general population, we are just beginning to understand that the complexities and interactions 
of endocrine signaling mechanisms include adipocytes and weight controlling mechanisms. Data are herein presented to provide evidence for a role of exposure to environmental chemicals during critical stages of differentiation (developmental "windows") and the development of obesity later in life.

\section{EXPERIMENTAL EVIDENCE FOR INVOLVEMENT OF EDCS IN OBESITY}

A link between endocrine disrupting chemicals and obesity had been proposed for a number of years. Nevertheless Baillie-Hamilton in 2002 published a landmark paper postulating a role for chemical toxins in the etiology of obesity by showing that the obesity epidemic coincided with the marked increase of industrial chemicals in the environment over the past 40 years. ${ }^{39}$ She further speculated that the current obesity epidemic could not be explained solely by alterations in food intake and/or decrease in physical activity. She cited numerous studies where chemicals including pesticides, organophosphates, polychlorinated biphenyls, polybrominated biphenyls, phthalates, bisphenol A, heavy metals, and some solvents caused weight gain, and proposed that these chemicals were interfering with weight homeostasis by altering weight-controlling hormones, altering sensitivity to neurotransmitters, or altering activity of the sympathetic nervous system..$^{39}$ It is interesting that in a few of the studies she cited, the chemicals were actually designed to have growth-promoting properties such as DES, which was widely used by the livestock industry specifically for this role. ${ }^{47}$

Since the Baille-Hamilton review, ${ }^{39}$ an increasing number of studies have been specifically designed to address the effects of environmental chemical exposure on weight gain and loss. Many studies have shown that exposure to various EDCs during critical periods of differentiation, at low environmentally-relevant doses, can alter developmental programming, resulting in obesity.

\section{Diethylstilbestrol (DES)}

DES, a potent synthetic estrogen, was widely prescribed to pregnant women from the 1940s through the 1970s in the mistaken belief that it could prevent threatened miscarriages. It was estimated that a range of 2 to 8 million pregnancies worldwide were exposed to DES. Today, it is well known that prenatal DES exposure resulted in a low but significant increase in neoplastic lesions and a high incidence of benign lesions in both the male and female offspring. The DES paradigm was a clear example that prenatal exposure could lead to adult-onset disease. To study the mechanisms involved in DES toxicity, we developed experimental mouse models of perinatal (prenatal or neonatal) DES exposure ${ }^{48}$ in which outbred mice were treated with DES on days 9-16 of gestation (the period of major organogenesis in the mouse $)^{49}$ or days 1-5 of neonatal life ${ }^{50,51}$ (a period of cellular differentiation of the reproductive tract and a critical period of immune, behavioral, and adipocyte differentiation). These perinatal DES animal models have successfully duplicated, and in some cases predicted, many of the alterations (structural, functional, cellular, and molecular) observed in similarly DES-exposed humans. ${ }^{51}$ Further, these models have also shown multigenerational transmission of disease patterns implicating epigenetic mechanisms in the transmission of these effects. ${ }^{52}$

Although our initial focus was on reproductive tract abnormalities and subfertility/infertility, we subsequently examined the relationship of perinatal DES treatment with the development of obesity later in life. We wanted to determine if DES was an "obesogen" as well as a reproductive toxicant and, if so, what were its molecular targets and the mechanisms through which it might act. For our obesity experiments, mice were treated with DES on days $1-5$ of neonatal life using a low dose of $0.001 \mathrm{mg} /$ day $(1 \mu \mathrm{g} / \mathrm{kg} / \mathrm{day}) ;$ this dose did not affect body weight during treatment but was associated with a significant increase in body weight in the adult animal by 4 to 6 months of age; male mice treated as neonates did not have an increase in body weight. ${ }^{41}$

Unlike the low dose of DES $(0.001 \mathrm{mg} / \mathrm{day}=1$ $\mu \mathrm{g} / \mathrm{kg} /$ day $)$, a higher dose $(1000 \mu \mathrm{g} / \mathrm{kg} / \mathrm{day}=1 \mathrm{mg} /$ $\mathrm{kg}$ /day) caused a significant decrease in body weight during treatment but it was followed by a "catch-up" period around puberty and then finally resulted in an increase in body weight of the DES-treated mice compared to controls after $\sim 2$ months of age. This "catch-up" in weight between treated and control animals is reminiscent of the thrifty phenotype which is a well known phenomenon in the field of nutrition 
and was described in human infants who received poor nutrition during fetal life but later had "catchup" growth that finally resulted in overweight and obesity later in life. ${ }^{53}$ Further studies indicated that the increase in body weight in DES-exposed mice was associated with an increase in the percent of body fat as determined by mouse densitometry. ${ }^{43,44}$

Increased body weight in both low and high DEStreated mice compared to controls was observed throughout adulthood; however, by 18 months of age, statistical differences in body weight between DES-treated mice and controls were difficult to show because individual animal variability within groups increased as they aged due to the altered health status of the DES animals. We concluded that since various doses of DES resulted in obesity whether or not pups were underweight during treatment, multiple pathways might be involved in the programming for obesity related to environmental estrogens.

Since densitometry images of DES-treated mice suggested excessive abdominal fat, specific fat pads were weighed to see if particular fat pads were affected by DES treatment or whether there was a generalized change throughout the mouse, since it is well known that increased abdominal fat is associated with cardiovascular disease and diabetes in humans. ${ }^{54}$ Weights of inguinal, parametrial, gonadal, and retroperitoneal fat pads were all increased in DES treated mice as compared to controls at 6-8 months of age, suggesting a potential impact on cardiovascular disease following developmental exposure to DES. Brown fat weights were not significantly different in these animals. ${ }^{42}$

Examination of DES-treated mice $(1000 \mu \mathrm{g} / \mathrm{kg} / \mathrm{day}$ $=1 \mathrm{mg} / \mathrm{kg} /$ day) and controls at 2 months of age, prior to the treated mice becoming overweight and obese, showed elevated serum levels of leptin, adiponectin, IL-6, and triglycerides, suggesting that these endpoints may be important early markers of subsequent adult disease. Elevated levels of leptin are not surprising considering the increase number and size of the adipocytes in the DES-treated mice, but the increase in adiponectin was not expected since low levels usually correlate with obesity and diabetes in humans. This may indicate insensitivity to these hormones and/or a loss of the negative feedback mechanisms that regulate adipogenesis. Nevertheless, additional studies are needed to determine the mechanisms involved. At 6 months of age, insulin and all of the serum markers except triglycerides were found to be significantly elevated as compared to controls. ${ }^{44}$

Glucose levels were also measured in DES (1000 $\mu \mathrm{g} / \mathrm{kg} / \mathrm{day}=1 \mathrm{mg} / \mathrm{kg} /$ day) and control mice at 2 months of age prior to the development of obesity and excessive weight gain. ${ }^{44}$ Interestingly, $25 \%$ of the DES-treated mice had significantly higher glucose levels than controls; these mice also showed a slower clearance rate of glucose from the blood since higher levels were seen throughout the experiment. ${ }^{44}$ Additional glucose measurements in older mice may help determine if a higher percentage of mice are affected with age and if higher and sustained levels of glucose can be demonstrated. To date, our data suggest that overweight and obesity observed in perinatal DES-treated mice will be associated with the development of diabetes, similar to the association of obesity with diabetes in humans. Further studies from our laboratory support a role for altered glucose metabolism as we have shown a high prevalence of islet cell hyperplasia in mice exposed to DES or other environmental estrogens including BPA and genistein (unpublished).

Since the imbalance of activity levels and food intake are known contributors to obesity, ambulatory activity was measured in DES $(1000 \mu \mathrm{g} / \mathrm{kg} / \mathrm{day}$ $=1 \mathrm{mg} / \mathrm{kg} /$ day) and control mice at 2 months of age before a difference in body weight could be detected. Overall, no statistical difference could be shown in activity between groups, although the DES group showed slightly less movement as compared to controls. This slight difference was not sufficient to explain the enhanced weight gain in DES mice as they aged. ${ }^{44}$

Food consumption was also assessed; DES-treated mice consumed more than controls over the course of the experiment ( $\sim 3$ grams more), but the amounts were not statistically different between the groups. ${ }^{44}$ Taking into account both the marginal decrease in activity and the increase in food intake in DES-treated mice as compared to controls, it is unlikely that these two parameters can solely explain the development of obesity in DES-treated mice.

A recent study indicated a role for developmental genes in the origins of obesity and body fat distribution 
in mice and humans. ${ }^{55}$ We examined whether exposure to environmental chemicals which exerted hormonal activity would alter expression of genes involved in programming adipocytes during development. Several genes were found to be implicated in altered adipocyte differentiation and function (Hoxa5, Gpc4, and Tbx15) as well as fat cell distribution (Thbd, $N r 2 f 1$, and Sfrp2). We investigated changes in gene expression by microarray analysis in uterine samples from DES-treated mice $(1000 \mu \mathrm{g} / \mathrm{kg} /$ day $=1 \mathrm{mg} / \mathrm{kg} /$ day $)$ compared to controls at 19 days of age. Genes involved in adipocyte differentiation were not different in the uterus following neonatal DES exposure. However, genes involved in fat distribution were altered; Thbd and $N r 2 f 1$ were significantly down-regulated and Sfrp2 was significantly up-regulated in DES-treated uteri compared to controls. ${ }^{56}$ These findings support the idea that environmental estrogens may play a role in regulating the expression of obesity-related genes in development. The identification of genes and molecular mechanisms that may be associated with EDCs and obesity is an exciting area of new research.

Although only neonatal exposure to DES has been discussed thus far in this review, exposure during prenatal life has also been shown to be associated with obesity later in life. Interestingly, high prenatal DES doses caused lower birth weight compared to controls, followed by a "catch-up period", finally resulting in obesity; low prenatal DES doses had no effect on birth weight but it still resulted in obesity later in life..$^{42}$ Thus, it appears that the effects of DES on adipocytes may depend on the time of exposure and the dose and that multiple mechanisms may be altered and result in the same obesity phenotype. Other investigators have also reported analogous findings with DES and other estrogenic chemicals. ${ }^{57}$

\section{Bisphenol A (BPA)}

BPA is a component of polycarbonate plastics and epoxy resins that is receiving much attention due to its high production volume (>800 million kilograms annually in the U.S. alone) and its widespread human exposure. ${ }^{58}$ It is used in the manufacture of numerous products and has been shown to leach from the linings of food cans, ${ }^{59}$ polycarbonate baby bottles and other beverage containers, ${ }^{60}$ and dental sealants and composites, ${ }^{61}$ suggesting that humans are routinely exposed to this chemical through numerous sources and routes of exposure. Further indication of human exposure is shown by studies reporting measurable BPA levels in human urine, ${ }^{62}$ serum,${ }^{63}$ breast milk, ${ }^{64}$ and maternal and fetal plasma, amniotic fluid, and placental tissues. ${ }^{65,66} \mathrm{BPA}$ is also halogenated (brominated or chlorinated) to produce flame retardants; tetrabromobisphenol A (TBBPA) is the most commonly used with $>60,000$ tons produced annually. ${ }^{67,68}$ Studies report that levels of brominated flame retardants are increasing in the serum of adults but, most importantly, the level in infants and children is markedly higher than in adults. ${ }^{69}$

BPA is often described as a "weak" estrogen; however, an emerging number of cellular and molecular studies found that it has potential for many other biological activities at low environmentally-relevant exposure levels. In addition to binding to the nuclear estrogen receptor (ER) alpha and ER beta, BPA interacts with a variety of other cellular targets including binding to a non-classical membrane-bound form of the ER (ncmER), a recently identified orphan nuclear receptor termed estrogen-related receptor gamma (ERR gamma), a seven-trans-membrane estrogen receptor called GPR30, and the aryl hydrocarbon receptor (AhR). Interactions with ncmER and ERR gamma are especially noteworthy because BPA binds to these receptors with high affinity. BPA has also been shown to act as an androgen receptor antagonist and to interact with thyroid hormone receptors (for review, see 70).

Experimental animal studies have reported that very low doses of BPA in the range of human exposures can exert effects if given during development. An increasing number of "low dose" studies have suggested that perinatal BPA exposure is associated with a variety of abnormalities in the male and female reproductive and mammary gland tissues (for review of low dose BPA effects, see ref 71, 72). Studies showing an association of BPA with obesity have received less attention. However, data from both mice and rats have shown increased body weight in animals that were exposed to low doses of BPA during prenatal and neonatal periods..$^{57,73-79}$ The latter study suggested that increase in body weight is gender-related, while other studies reported effects in both males and females. The diversity may be related to the timing of 
exposure and dose. Together these studies indicate variable sensitivity to disruption by environmental chemicals during the developmental period and underscore the complexity of the mechanisms involved in the development of obesity.

In vitro studies with BPA provide further evidence for a role of this chemical in the development of obesity and moreover suggest specific targets; BPA causes 3T3-L1 cells (mouse fibroblast cells that can differentiate into adipocytes) to increase their rate of differentiation, ${ }^{80}$ and, in combination with insulin, accelerates adipocyte formation. ${ }^{81,82}$ Other in vitro studies also show that low doses of BPA, similar to DES, impair calcium signaling in pancreatic alpha cells, disrupt beta cell function, and cause insulin resistance.$^{83,84}$ Low environmentally-relevant doses of BPA have also been reported to inhibit adiponectin synthesis and to stimulate the release of inflammatory adipokines such as interleukin-6 (IL-6) and tumor necrosis factor alpha (TNF- $\alpha$ ) from human adipose tissue, suggesting that BPA is involved in obesity and the related metabolic syndrome. ${ }^{85,86}$

Studies have also linked BPA exposure to disruption of pancreatic beta-cell function and blood glucose homeostasis in mice, ${ }^{87}$ suggesting that experimental animals are affected by BPA.

\section{Phytoestrogens}

In recent years, efforts to implement healthier eating lifestyles have resulted in an increased consumption of soy products and soy supplements which in turn has caused increased exposure to phytoestrogens. Although a diet high in phytoestrogens, and low in fat, has been considered a treatment or a preventive means against obesity, phytoestrogens may also play a role in causing the disease. Genistein and daidzein are two of the most abundant phytoestrogens ${ }^{88}$ in the human diet, and genistein, because of its estrogenic activity, has been proposed as having a role in the maintenance of health by regulating lipid and carbohydrate homeostasis. However, a recent study showed that genistein at pharmacologically high doses did indeed inhibit adipose tissue fat deposition, while at low doses, similar to those found in Western and Eastern diets, in soy milk or in food supplements containing soy, it induced increased adipose tissue fat deposition, especially in males. ${ }^{89}$ Further, this increase in adipose tissue fat deposition by genistein was correlated with mild peripheral insulin resistance. Similarly to our findings with DES, genistein did not significantly affect food consumption, suggesting an abnormal programming of factors involved in weight homeostasis.$^{89}$ Although additional research is needed, the data thus far suggest that genistein can affect adipose tissue fat deposition and that the effects are dose-dependent and gender specific.

Developmental exposure to numerous naturally estrogenic substances has been studied and their effects on body weight are well documented, including increased body weight caused by genistein, resveratrol, and zearalenone. ${ }^{57}$ Phytoestrogens, both singly or in combination with other chemicals, have multiple pathways of action and are likely involved in adipogenesis and energy metabolism. Whether they have beneficial or harmful effects remains to be determined, but their effect probably depends on timing of exposure and dose.

\section{Tributyltin (TBT)}

Another novel and interesting class of EDCs is called organotins and includes persistent organic pollutants. TBT chloride and triphenyltin chloride have been identified as nanomolar agonist ligands for retinoid $\mathrm{X}$ receptor $(\mathrm{RXR})$ and peroxisome proliferators-activated receptor $\gamma(\operatorname{PPAR} \gamma)$, nuclear receptors that play important roles in lipid homeostasis and adipogenesis; TBT has been shown to disrupt normal development and homeostatic controls over adipogenesis and energy balance, resulting in obesity. ${ }^{45,46}$ Interestingly, TBT was shown to cause permanent physiological changes in both male and female mice exposed during prenatal development, resulting in a predisposition for weight gain. The mechanisms describing how these chemicals actually program for the development of obesity has been eloquently described. ${ }^{90}$ The mechanisms involved in organotins and estrogenic EDCs are different and this fact points to the complexity of the disease and the multiple mechanisms and targets involved in obesity.

\section{Other Chemicals}

An overview of the toxicology literature suggests that exposure to many other environmental chemicals, including pesticides, can cause weight gain; for exam- 
ple, organochlorines such as DDT, endrin, lindane, and hexachlorobenzene; organophosphates; carbamates; polychlorinated biphenyls; polybrominated biphenyls which are used as fire retardants; other plastic components such as phthalates; perfluoroctanoic acid (PFOA); heavy metals such as cadmium, lead, and arsenic; and solvents (for review, ref 39). The weight gain associated with these chemicals tends to occur at low levels of exposure, not at high doses in which most toxicity studies have been conducted. The exact mechanisms that may induce these chemicals to cause weight gain are not known but may involve altered thyroid function metabolism and/or energy homeostasis. Interestingly, a recent paper reported that PFOA is associated with current thyroid diseases in the US. ${ }^{91}$

Many pharmaceuticals also play a role in altered weight homeostasis and metabolism and/or altered hormone levels; in fact, many prescribed drugs have the unwanted side effects of weight gain and they include drugs commonly used in oncology, cardiology, immunology, and psychiatry. ${ }^{39}$ While these medicines are normally prescribed for adults in which their effects on weight gain would most like be reversible, disappearing when medication ceased, the possible impact on the unborn fetus and young child should not be underestimated since, when exposure occurs during development, the effects would likely be permanent and non-reversible.

\section{PROPOSED MODES OF ACTION}

Endocrine disrupting chemicals probably exert their effects through a variety of mechanisms. However, the most commonly proposed mechanism involves direct binding to nuclear receptors such as estrogen receptor $\alpha$ and/or PPAR $\gamma$ acting as agonists. Alternatively, they could bind to nuclear receptors and act as antagonists. Endocrine disruptors could also act indirectly; for example, they could disrupt hormone levels by inhibiting enzymatic activity such as the P450 family members CYP19 and CYP3A1, which convert testosterone to estradiol, or by activating expression of the P450 enzymes. Finally, another mechanism that has been proposed is altering neuronal synapse formation ${ }^{92}$ which could affect release of brain-produced substances that bind to nuclear receptors and may affect energy regulation. An additional complexity is that these proposed mechanisms may be interacting with each other. Further, the exact target tissue is unknown and probably involves multiple target sites; after all, adipocytes are endocrine cells and they produce and receive endocrine signals from numerous other endocrine tissues in the body. The altered signal or tissue may involve adipocytes, brain, liver, stomach, pancreas, etc. Identifying the mechanisms whereby EDCs influence weight homeostasis and energy balance is an important area of future research.

\section{SUMMARY AND CONCLUSIONS}

The data included in this review support the notion that brief exposure early in development to environmental chemicals with estrogenic activity increases body weight gain with age and alters markers predictive of obesity in experimental animals. Furthermore, epidemiologic studies support the findings in experimental animals and show a link between exposure to environmental chemicals (such as estrogenic chemicals, BPA, PCBs, DDE, and persistent organic pollutants and heavy metals) and the development of obesity. ${ }^{39,40}$ Importantly, the use of soy-based infant formula containing the estrogenic component genistein has been positively associated with obesity later in life. ${ }^{93}$ Using the DES animal model as an important research tool to study "obesogens", the mechanisms involved in altered weight homeostasis (direct and/or through endocrine feedback loops, i.e., ghrelin, leptin, etc.) by environmental estrogens can be elucidated. ${ }^{41-44}$ In addition, this animal model may shed light on areas of prevention. Public health risks can no longer be based on the assumption that overweight and obesity are just personal choices involving the quantity and kind of foods we eat combined with inactivity. It is quite possible that complex events, including exposure to environmental chemicals during development, may be contributing to the obesity epidemic.

\section{REFERENCES}

1. Ogden CL, Yanovski SZ, Carroll MD, Flegal KM, 2007 The epidemiology of obesity. Gastroenterology 132: 2087-2102.

2. Oken E, Gillman MW, 2003 Fetal origins of obesity. Obes Res 11: 496-506.

3. Cunningham E, 2010 Where can I find obesity statistics? 
J Am Diet Assoc 110: 656.

4. Caballero B, 2007 The global epidemic of obesity: an overview. Epidemiol Rev 29: 1-5.

5. CDC. Report on overweight and obesity, $2008 \mathrm{http}: / /$ www.cdc.gov/nccdphp/dnpa/obesity. In: Centers for Disease Control and Prevention

6. McAllister EJ, Dhurandhar NV, Keith SW, et al, 2009 Ten putative contributors to the obesity epidemic. Crit Rev Food Sci Nutr 49: 868-913.

7. Ogden CL, Flegal KM, Carroll MD, Johnson CL, 2002 Prevalence and trends in overweight among US children and adolescents, 1999-2000. JAMA 288: 1728-1732.

8. Flegal KM, Carroll MD, Ogden CL, Curtin LR, 2010 Prevalence and trends in obesity among US adults, 1999-2008. JAMA 303: 235-241.

9. Collins S, 2005 Overview of clinical perspectives and mechanisms of obesity. Birth Defects Res A Clin Mol Teratol 73: 470-471.

10. Mokdad AH, Ford ES, Bowman BA, et al, 2003 Prevalence of obesity, diabetes, and obesity-related health risk factors, 2001. JAMA 289: 76-79.

11. Mokdad AH, Serdula MK, Dietz WH, Bowman BA, Marks JS, Koplan JP, 1999 The spread of the obesity epidemic in the United States, 1991-1998. JAMA 282: 1519-1522.

12. Goncharov A, Haase RF, Santiago-Rivera A, et al, 2008 High serum PCBs are associated with elevation of serum lipids and cardiovascular disease in a Native American population. Environ Res 106: 226-239.

13. Gladen BC, Ragan NB, Rogan WJ, 2000 Pubertal growth and development and prenatal and lactational exposure to polychlorinated biphenyls and dichlorodiphenyl dichloroethene. J Pediatr 136: 490-496.

14. Vasiliu O, Cameron L, Gardiner J, Deguire P, Karmaus W, 2006 Polybrominated biphenyls, polychlorinated biphenyls, body weight, and incidence of adult-onset diabetes mellitus. Epidemiology 17: 352-359.

15. Lee DH, Lee IK, Jin SH, Steffes M, Jacobs DR, Jr, 2007 Association between serum concentrations of persistent organic pollutants and insulin resistance among nondiabetic adults: results from the National Health and Nutrition Examination Survey 1999-2002. Diabetes Care 30: 622-628.

16. Lee DH, Steffes MW, Jacobs DR, Jr, 2008 Can persistent organic pollutants explain the association between serum gamma-glutamyltransferase and type 2 diabetes? Diabetologia 51: 402-407.

17. Pelletier C, Doucet E, Imbeault P, Tremblay A, 2002 Associations between weight loss-induced changes in plasma organochlorine concentrations, serum $\mathrm{T}(3)$ concentration, and resting metabolic rate. Toxicol Sci 67: 46-51.

18. Smink A, Ribas-Fito N, Garcia R, et al, 2008 Exposure to hexachlorobenzene during pregnancy increases the risk of overweight in children aged 6 years. Acta Paediatr
97: 1465-1469.

19. Stahlhut RW, van Wijngaarden E, Dye TD, Cook S, Swan SH, 2007 Concentrations of urinary phthalate metabolites are associated with increased waist circumference and insulin resistance in adult U.S. males. Environ Health Perspect 115: 876-882.

20. Hatch EE, Nelson JW, Qureshi MM, et al, 2008 Association of urinary phthalate metabolite concentrations with body mass index and waist circumference: a crosssectional study of NHANES data, 1999-2002. Environ Health 7: 27.

21. Takeuchi T, Tsutsumi O, Ikezuki Y, Takai Y, Taketani Y, 2004 Positive relationship between androgen and the endocrine disruptor, bisphenol A, in normal women and women with ovarian dysfunction. Endocr J 51: 165-169.

22. Coronado-Gonzalez JA, Del Razo LM, Garcia-Vargas G, Sanmiguel-Salazar F, Escobedo-de la Pena J, 2007 Inorganic arsenic exposure and type 2 diabetes mellitus in Mexico. Environ Res 104: 383-389.

23. Navas-Acien A, Silbergeld EK, Pastor-Barriuso R, Guallar E, 2008 Arsenic exposure and prevalence of type 2 diabetes in US adults. JAMA 300: 814-822.

24. Bern B, 1992 The Fragile Fetus. Princeton, NJ: Princeton Scientific Publishing Co.

25. Heindel JJ, 2007 Role of exposure to environmental chemicals in the developmental basis of disease and dysfunction. Reprod Toxicol 23: 257-259.

26. Heindel JJ, 2008 Animal models for probing the developmental basis of disease and dysfunction paradigm. Basic Clin Pharmacol Toxicol 102: 76-81.

27. Heindel JJ, Levin E, 2005 Developmental origins and environmental influences--Introduction. NIEHS symposium. Birth Defects Res A Clin Mol Teratol 73: 469.

28. Gluckman PD, Hanson MA, 2004 The developmental origins of the metabolic syndrome. Trends Endocrinol Metab 15: 183-187.

29. Colborn T, Dumanoski D, Myers JP, 1996. In Our Stolen Future. Penguin Books USA, Inc.

30. NIH, 1999 DES Research Update, NIH Publication No. 00-4722, Bethesda, MD.

31. Barker DJ, Eriksson JG, Forsen T, Osmond C, 2002 Fetal origins of adult disease: strength of effects and biological basis. Int J Epidemiol 31: 1235-1239.

32. vom Saal FS, Akingbemi BT, Belcher SM, et al, 2007 Chapel Hill bisphenol A expert panel consensus statement: integration of mechanisms, effects in animals and potential to impact human health at current levels of exposure. Reprod Toxicol 24: 131-138.

33. Anway MD, Cupp AS, Uzumcu M, Skinner MK, 2005 Epigenetic transgenerational actions of endocrine disruptors and male fertility. Science 308: 1466-1469.

34. Anway MD, Skinner MK, 2008 Epigenetic programming of the germ line: effects of endocrine disruptors on the development of transgenerational disease. Reprod 
Biomed Online 16: 23-25.

35. Newbold RR, Padilla-Banks E, Jefferson WN, 2006 Adverse effects of the model environmental estrogen diethylstilbestrol are transmitted to subsequent generations. Endocrinology 147: S11-17.

36. Skinner MK, Anway MD, 2007 Epigenetic transgenerational actions of vinclozolin on the development of disease and cancer. Crit Rev Oncog 13: 75-82.

37. Skinner MK, Anway MD, Savenkova MI, Gore AC, Crews D, 2008 Transgenerational epigenetic programming of the brain transcriptome and anxiety behavior. PLoS One 3: e3745.

38. Tang WY, Newbold R, Mardilovich K, et al, 2008 Persistent hypomethylation in the promoter of nucleosomal binding protein 1 (Nsbp1) correlates with overexpression of Nsbp1 in mouse uteri neonatally exposed to diethylstilbestrol or genistein. Endocrinology 149: 5922-5931.

39. Baillie-Hamilton PF, 2002 Chemical toxins: a hypothesis to explain the global obesity epidemic. J Altern Complement Med 8: 185-192.

40. Heindel JJ, 2003 Endocrine disruptors and the obesity epidemic. Toxicol Sci 76: 247-249.

41. Newbold RR, Padilla-Banks E, Jefferson WN, Heindel JJ, 2008 Effects of endocrine disruptors on obesity. Int J Androl 31: 201-208.

42. Newbold RR, Padilla-Banks E, Snyder RJ, Jefferson WN, 2005 Developmental exposure to estrogenic compounds and obesity. Birth Defects Res A Clin Mol Teratol 73: 478-480.

43. Newbold RR, Padilla-Banks E, Snyder RJ, Jefferson WN, 2007 Perinatal exposure to environmental estrogens and the development of obesity. Mol Nutr Food Res 51: 912-917.

44. Newbold RR, Padilla-Banks E, Snyder RJ, Phillips TM, Jefferson WN, 2007 Developmental exposure to endocrine disruptors and the obesity epidemic. Reprod Toxicol 23: 290-296.

45. Grun F, Blumberg B, 2006 Environmental obesogens: organotins and endocrine disruption via nuclear receptor signaling. Endocrinology 147: S50-55.

46. Grun F, Watanabe H, Zamanian Z, et al, 2006 Endocrinedisrupting organotin compounds are potent inducers of adipogenesis in vertebrates. Mol Endocrinol 20: 21412155 .

47. Raun A, Preston R. History of diethylstilbestrol use in livestock. http://www.asas.org/oldsite/Bios/Raunhist. pdf 2002.

48. Newbold RR, 1995 Cellular and molecular effects of developmental exposure to diethylstilbestrol: implications for other environmnetal estrogens. Environmental Health Perspectives 103: 83-87.

49. McLachlan JA, Newbold RR, Bullock BC, 1980 Longterm effects on the female mouse genital tract associated with prenatal exposure to diethylstilbestrol. Cancer
Research 40: 3988-3999.

50. Newbold RR, Bullock BC, McLachlan JA, 1990 Uterine adenocarcinoma in mice following developmental treatment with estrogens: a model for hormonal carcinogenesis. Cancer Research 50: 7677-7681.

51. Newbold R, 2004 Lessons Learned from Perinatal Exposure to Diethylstilbestrol (DES). Toxicology and Applied Pharmacology 199: 142-150.

52. Newbold RR, McLachlan JA, 1996 Transplacental hormonal carcinogenesis: diethylstilbestrol as an example. In: Huff J, Boyd J, Barrett JC (eds.), Cellular and Molecular Mechanisms of Hormonal Carcinogenesis: Environmental Influences. New York: Wiley-Liss; pp 131-147.

53. Gluckman PD, Hanson MA, Pinal C, 2005 The developmental origins of adult disease. Matern Child Nutr 1: $130-141$.

54. Gillum RF, 1987 The association of the ratio of waist to hip girth with blood pressure, serum cholesterol and serum uric acid in children and youths aged 6-17 years. J Chronic Dis 40: 413-420.

55. Gesta S, Bluher M, Yamamoto Y, et al, 2006 Evidence for a role of developmental genes in the origin of obesity and body fat distribution. Proc Natl Acad Sci U S A 103: 6676-6681.

56. Newbold RR, Jefferson WN, Grissom SF, Padilla-Banks E, Snyder RJ, Lobenhofer EK, 2007 Developmental exposure to diethylstilbestrol alters uterine gene expression that may be associated with uterine neoplasia later in life. Mol Carcinog 46: 783-796.

57. Nikaido Y, Yoshizawa K, Danbara N, et al, 2004 Effects of maternal xenoestrogen exposure on development of the reproductive tract and mammary gland in female CD-1 mouse offspring. Reprod Toxicol 18: 803-811.

58. Zoeller RT, Bansal R, Parris C, 2005 Bisphenol-A, an environmental contaminant that acts as a thyroid hormone receptor antagonist in vitro, increases serum thyroxine, and alters RC3/neurogranin expression in the developing rat brain. Endocrinology 146: 607-612.

59. Brotons JA, Olea-Serrano MF, Villalobos M, Olea N, 1994 Xenoestrogens released from lacquer coating in food cans. Environmental Health Perspectives 103: 608-612.

60. Biles JE, McNeal TP, Begley TH, Hollifield HC, 1997 Determination of bisphenol-A in reusable polycarbonate food-contact plastics and migration to food simulating liquids. Journal Agric Food Chem 45: 3541-3544.

61. Olea N, Pulgar R, Perez P, et al, 1996, Estrogenicity of resin-based composites and sealants used in dentistry. Environ Health Perspect 104: 298-305.

62. Calafat AM, Ye X, Wong LY, Reidy JA, Needham LL, 2008 Exposure of the U.S. population to bisphenol A and 4-tertiary-octylphenol: 2003-2004. Environ Health Perspect 116: 39-44.

63. Takeuchi T, Tsutsumi O, 2002 Serum bisphenol a con- 
centrations showed gender differences, possibly linked to androgen levels. Biochem Biophys Res Commun 291: 76-78.

64. Ye X, Kuklenyik Z, Needham LL, Calafat AM, 2006 Measuring environmental phenols and chlorinated organic chemicals in breast milk using automated on-line column-switching-high performance liquid chromatography-isotope dilution tandem mass spectrometry. J Chromatogr B Analyt Technol Biomed Life Sci 831: 110-115.

65. Padmanabhan V, Siefert K, Ransom S, et al, 2008 Maternal bisphenol-A levels at delivery: a looming problem? J Perinatol 28: 258-263.

66. Schonfelder G, Flick B, Mayr E, Talsness C, Paul M, Chahoud I, 2002 In utero exposure to low doses of bisphenol A lead to long-term deleterious effects in the vagina. Neoplasia 4: 98-102.

67. Tetrabromobisphenol A and derivatives: Environmental Health Criteria no. 172. In. Geneva: World Health Organization; 1995.

68. European Union Updated European Risk Assessment Report 4,4'-Isopropylidenediphenol (Bisphenol A). Environment Addendum of February 2008 (to be read in conjunction withEU RAR of BPA published in 2003). http:ecb.jrc.it/documents/Existing-Chemicals/RISKASSESSMENT/ADDENDUM/bisphenola add 325. pdf). In; 2008.

69. Thomsen C, Lundanes E, Becher G, 2002 Brominated flame retardants in archived serum samples from Norway: a study on temporal trends and the role of age. Environ Sci Technol 36: 1414-1418.

70. Wetherill YB, Akingbemi BT, Kanno J, et al, 2007 In vitro molecular mechanisms of bisphenol A action. Reprod Toxicol 24: 178-198.

71. NTP. CEHR Brief on Bisphenol A. National Toxicology Program, Research Triangle Park, NC. 2008.

72. Richter CA, Birnbaum LS, Farabollini F, et al, 2007 In vivo effects of bisphenol A in laboratory rodent studies. Reprod Toxicol 24: 199-224.

73. Howdeshell KL, Hotchkiss AK, Thayer KA, Vandenbergh JG, vom Saal FS, 1999 Exposure to bisphenol A advances puberty. Nature 401: 763-764.

74. Ashby J, Tinwell H, Haseman J, 1999 Lack of effects for low dose levels of bisphenol A and diethylstilbestrol on the prostate gland of CF1 mice exposed in utero. Regul Toxicol Pharmacol 30: 156-166.

75. Takai Y, Tsutsumi O, Ikezuki Y, et al, 2001 Preimplantation exposure to bisphenol A advances postnatal development. Reprod Toxicol 15: 71-74.

76. Honma S, Suzuki A, Buchanan DL, Katsu Y, Watanabe $\mathrm{H}$, Iguchi T, 2002 Low dose effect of in utero exposure to bisphenol A and diethylstilbestrol on female mouse reproduction. Reprod Toxicol 16: 117-122.

77. Nikaido Y, Danbara N, Tsujita-Kyutoku M, Yuri T, Uehara N, Tsubura A, 2005 Effects of prepubertal expo- sure to xenoestrogen on development of estrogen target organs in female CD-1 mice. In Vivo 19: 487-494.

78. Rubin BS, Murray MK, Damassa DA, King JC, Soto AM, 2001 Perinatal exposure to low doses of bisphenol A affects body weight, patterns of estrous cyclicity, and plasma LH levels. Environ Health Perspect 109: 675680 .

79. Somm E, Schwitzgebel VM, Toulotte A, et al, 2009 Perinatal exposure to bisphenol a alters early adipogenesis in the rat. Environ Health Perspect 117: 1549-1555.

80. Sakurai K, Kawazuma M, Adachi T, et al, 2004 Bisphenol A affects glucose transport in mouse 3T3-F442A adipocytes. Br J Pharmacol 141: 209-214.

81. Masuno H, Kidani T, Sekiya K, et al, 2002 Bisphenol A in combination with insulin can accelerate the conversion of 3T3-L1 fibroblasts to adipocytes. J Lipid Res 43: 676-684.

82. Masuno H, Iwanami J, Kidani T, Sakayama K, Honda K, 2005 Bisphenol a accelerates terminal differentiation of 3T3-L1 cells into adipocytes through the phosphatidylinositol 3-kinase pathway. Toxicol Sci 84: 319-327.

83. Alonso-Magdalena P, Laribi O, Ropero AB, et al, 2005 Low doses of bisphenol A and diethylstilbestrol impair $\mathrm{Ca} 2+$ signals in pancreatic alpha-cells through a nonclassical membrane estrogen receptor within intact islets of Langerhans. Environ Health Perspect 113: 969-977.

84. Alonso-Magdalena P, Morimoto S, Ripoll C, Fuentes E, Nadal A, 2006 The estrogenic effect of bisphenol A disrupts pancreatic beta-cell function in vivo and induces insulin resistance. Environ Health Perspect 114: 106-112.

85. Ben-Jonathan N, Hugo ER, Brandebourg TD, 2009 Effects of bisphenol A on adipokine release from human adipose tissue: Implications for the metabolic syndrome. Mol Cell Endocrinol 304: 49-54.

86. Hugo ER, Brandebourg TD, Woo JG, Loftus J, Alexander JW, Ben-Jonathan N, 2008 Bisphenol A at environmentally relevant doses inhibits adiponectin release from human adipose tissue explants and adipocytes. Environ Health Perspect 116: 1642-1647.

87. Ropero AB, Alonso-Magdalena P, Garcia-Garcia E, Ripoll C, Fuentes E, Nadal A, 2008 Bisphenol-A disruption of the endocrine pancreas and blood glucose homeostasis. Int J Androl 31: 194-200.

88. Moutsatsou P, 2007 The spectrum of phytoestrogens in nature: our knowledge is expanding. Hormones (Athens) 6: 173-193.

89. Penza M, Montani C, Romani A, et al, 2006 Genistein affects adipose tissue deposition in a dose-dependent and gender-specific manner. Endocrinology 147: 57405751 .

90. Tabb MM, Blumberg B, 2006 New modes of action for endocrine-disrupting chemicals. Mol Endocrinol 20: 475-482.

91. Melzer D, Rice N, Depledge MH, Henley WE, Galloway 
TS, 2010 association between serum perfluoroctanoic acid (PFOA) and Thyroid Disease in the U.S. National Health and Nutrition Examination Survey. Environ Health Perspect 118: 686-692.

92. Shinomiya N, Shinomiya M, 2003 Dichlorodiphenyltrichloroethane suppresses neurite outgrowth and induces apoptosis in PC12 pheochromocytoma cells. Toxicol Lett 137: 175-183.

93. Stettler N, Stallings VA, Troxel AB, et al, 2005 Weight gain in the first week of life and overweight in adulthood: a cohort study of European American subjects fed infant formula. Circulation 111: 1897-1903. 